\title{
Hepatocellular Carcinoma Causing Jaundice by a Tumor Biliary Emboli: A Case Report and a Review of Literature
}

\author{
Christian Saliba ${ }^{1}$, Zeina Sawaya ${ }^{2}$, Julien El Sayegh ${ }^{1}$, Mohamad Raka ${ }^{3}$, Samer Diab ${ }^{1}$, Antoine Abou Rached ${ }^{4}$ and \\ Raja Wakim ${ }^{3}$
}

${ }^{1}$ Department of General Surgery , Lebanese American University Medical Center, Lebanon

${ }^{2}$ Department of General Surgery, Saint Charles Hospital, Lebanon

${ }^{3}$ Department of General Surgery, Mount Lebanon Hospital, Lebanon

${ }^{4}$ Department of Gastroenterology, Saint Charles Hospital, Lebanon

Submission: December 06, 2018; Published: December 14, 2018

*Corresponding author: Christian Saliba, Department of General Surgery, Lebanese American University Medical Center, Lebanese American University, Faculty of Medicine, Beirut, Lebanon

\begin{abstract}
Hepatocellular carcinomas arising from healthy hepatic tissue are frequent, however, they rarely manifest themselves by obstructive jaundice. The clinical scenario presenting with jaundice and a degenerative liver mass orients us more towards acute infectious cholangitis with liver abscess. However, a hepatocellular carcinoma (HCC) with tumor biliary emboli can mimic this clinical presentation. The authors here report this rare case of HCC with metastatic tumor emboli in the biliary tree and analyze it in order to highlight this rare entity and offer a management plan despite the lack of literature concerning this specific topic.
\end{abstract}

Keywords: Hepatocellular carcinoma; Obstructive jaundice; Metastatic emboli; Tumor emboli; Endoscopic retrograde cholangiopancreatography; Magnetic resonance cholangiopancreatography

Abbreviations: HCC: Hepatocellular Carcinoma; ERCP: Endoscopic Retrograde Cholangiopancreatography; AFP: Alpha Feto Protein; CT: Computed Tomography; PTC: Percutaneous Transhepatic Cholangiography

\section{Introduction}

Hepatocellular carcinoma (HCC) is the fifth most common cancer worldwide [1], with an incidence of one million new cases every year. Most commonly encountered in areas endemic with hepatitis B or C. Jaundice associated with HCC, usually manifests itself at an advanced stage of the disease, generally with liver failure, due to an underlying cirrhosis or diffuse tumor infiltration of the liver parenchyma. In these cases, prognosis is usually dramatically harsh. However, HCC associated obstructive jaundice, due to intraluminal obstruction of the biliary tree by a tumor emboli or blood clot (hemobilia) or extrinsic compression by tumor compression, represent only $0.5-1.3 \%$ (or $13 \%$ check references) of all cases [1-3]. Diagnosing HCC associated obstructive jaundice is of extreme importance because their surgical management is beneficial with a more favorable prognosis than jaundice associated to liver failure by tumor spread [4].

\section{Case Presentation}

This is the case of a 67-year-old female who presented with Charcot's triad of right upper quadrant pain, jaundice and fever. Her past medical history is notable for Diabetes mellitus type II, hypertension, dyslipidemia. Her past surgical history is notable for a laparoscopic cholecystectomy done 2 years ago with a normal post-operative follow up. She had similar symptoms a year ago and benefited from 2 endoscopic retrograde cholangiopancreatography (ERCP) with sphincterotomy and extraction of choledocolithiasis. A month prior to her current hospitalization, the second ERCP was performed for jaundice and recurrent fever, with extraction of biliary debris. Her symptoms persisted following the second ERCP, which prompted her admission for further investigations.

Clinically, she presented with fever (38C), jaundice and tenderness upon palpation of the right upper quadrant. Laboratory exams showed alteration of her liver function tests: bilirubin total / bilirubin direct $=6.6 / 3.9 \mathrm{mg} / \mathrm{dl}$ (normal $<1.5 /<0.5$ ), Gamma GT $=377 \mathrm{U} / \mathrm{l}($ normal $<80)$, Alkaline phosphatase $=271 \mathrm{U} / \mathrm{l}$ (normal $<140$ ). Serologies for hepatitis B and C were negative. Abdominal ultrasound was done and showed a hypoechoic lesion of the left liver measuring at $38 \mathrm{~mm}$ that correspond to a liver abscess (Figure 1); no dilation of the intra and extra hepatic biliary tree was present. A magnetic resonance cholangiopancreatography 


\section{Juniper Online Journal of Case Studies}

(MRCP) revealed an irregular $2 \mathrm{~cm}$ biliary tree stenosis located at the common hepatic duct and another stenosis located at the left hepatic branch (Figure 2). A circular $4 \mathrm{~cm}$ lesion was located at the level of segment II and segment III that may correspond to a liver abscess associated with multiple micro abscesses (Figure 3).

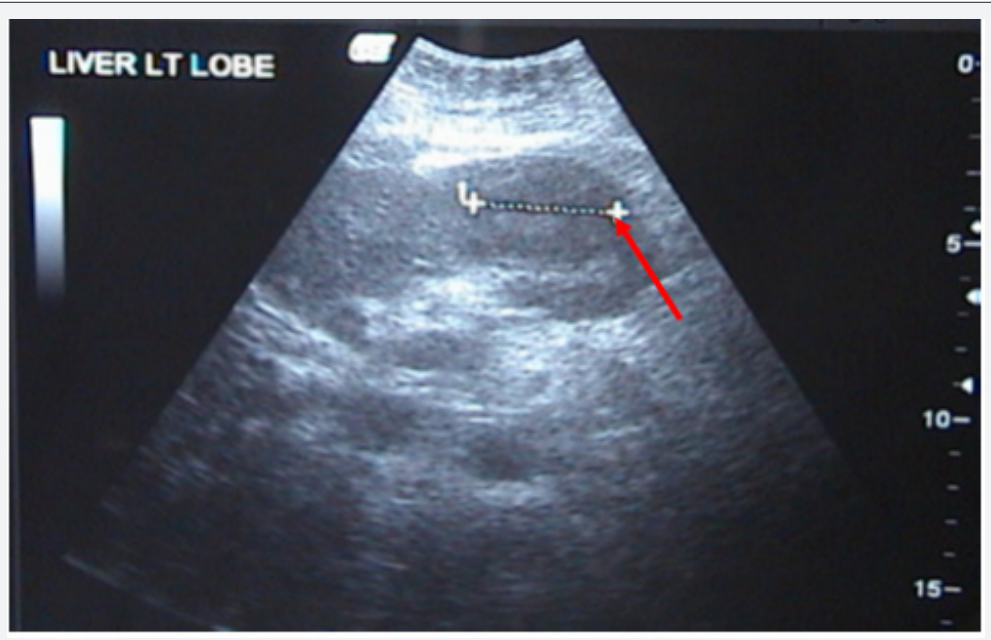

Figure 1: Image of an abdominal ultrasound showing a hypoechoic lesion of the left liver measuring 38mm in diameter corresponding to a liver abscess.

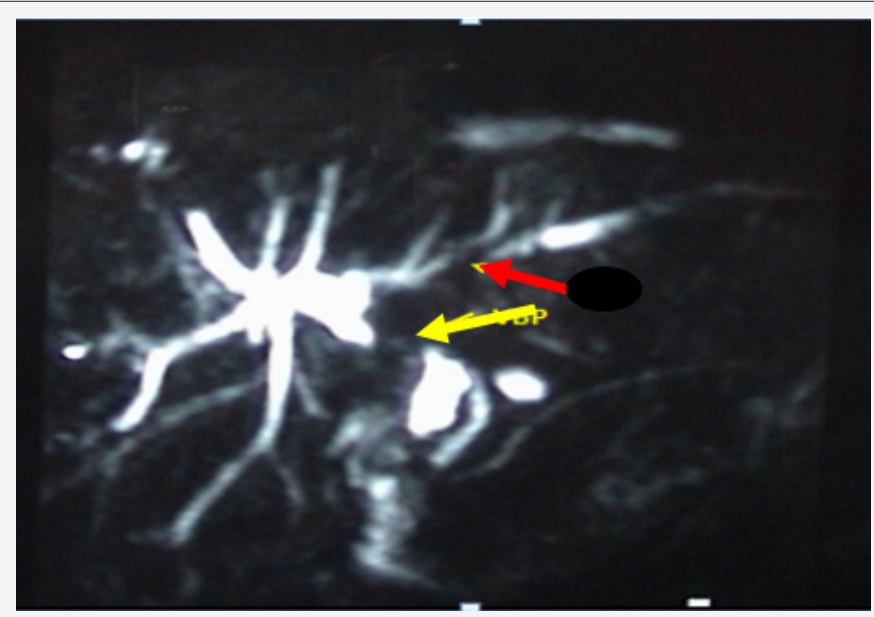

Figure 2: MRCP image showing an irregular $2 \mathrm{~cm}$ stenosis on the common bile duct (yellow arrow) and another stenosis on the left hepatic duct (red arrow).

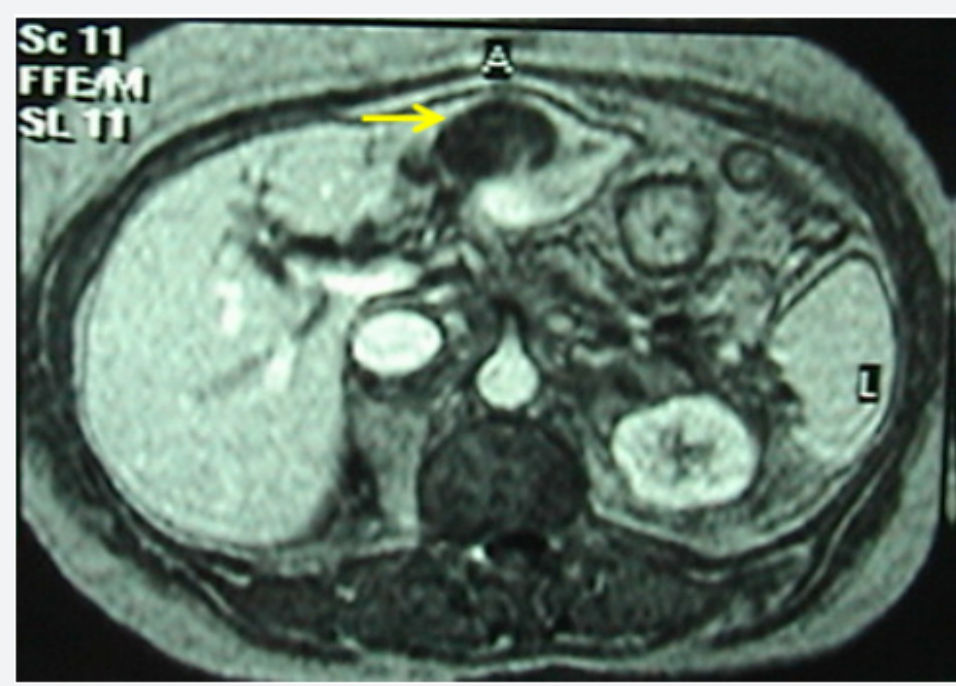

Figure 3: MRCP image showing a 4cm lesion (yellow arrow) at the level of segments II and III. 


\section{Juniper Online Journal of Case Studies}

An acute cholangitis, with a left liver abscess causing intra and extra hepatic biliary tree dilation were then diagnosed.

A computed tomography (CT) guided drainage of the liver abscess with liver biopsy were performed with necrotic material being drained (Figure 4). Culture came back negative and pathology showed normal liver tissue with inflammatory changes corresponding to cholestasis. 5 days later, we repeated the ERCP and a lacunar image occupying the common hepatic bile duct was identified (Figure 5). Biliary debris were extracted, along with $0.5 \mathrm{~cm}$ stone, and a repermeabilisation of the biliary tree was noted. The lacunar shaped image was however still present, along with an amputation of the left hepatic duct (Figure 6). 48 hours later, we had a clinical aggravation of the patient's jaundice and fever. Alpha Feto protein (AFP) and CA 19-9 came back 2000-3000 times the normal limit.

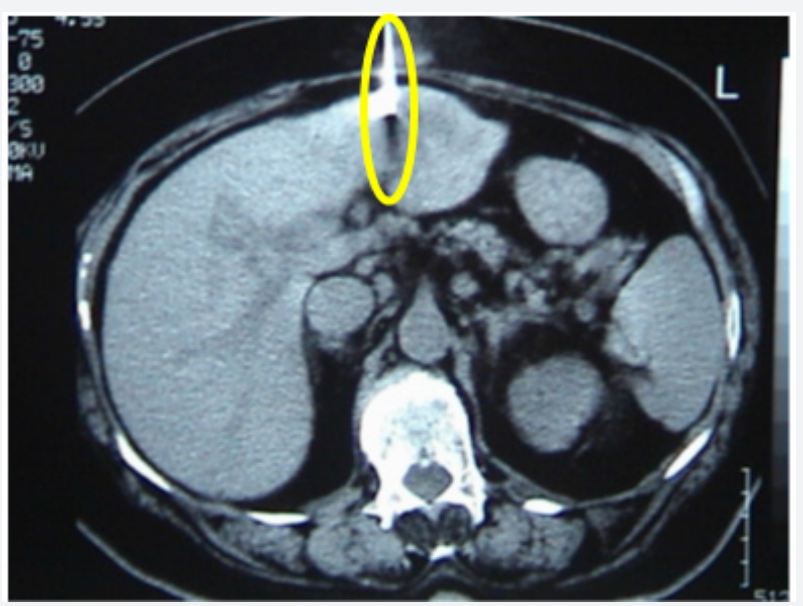

Figure 4: CT imaging showing a guided drainage (yellow oval) of the abscess.

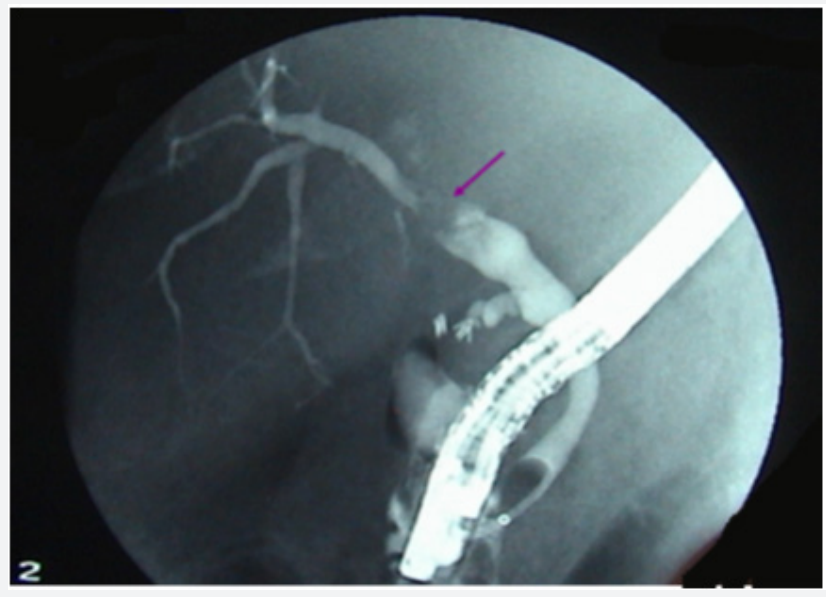

Figure 5: ERCP imaging showing a lacunar stenotic lesion of the common hepatic duct (purple arrow).

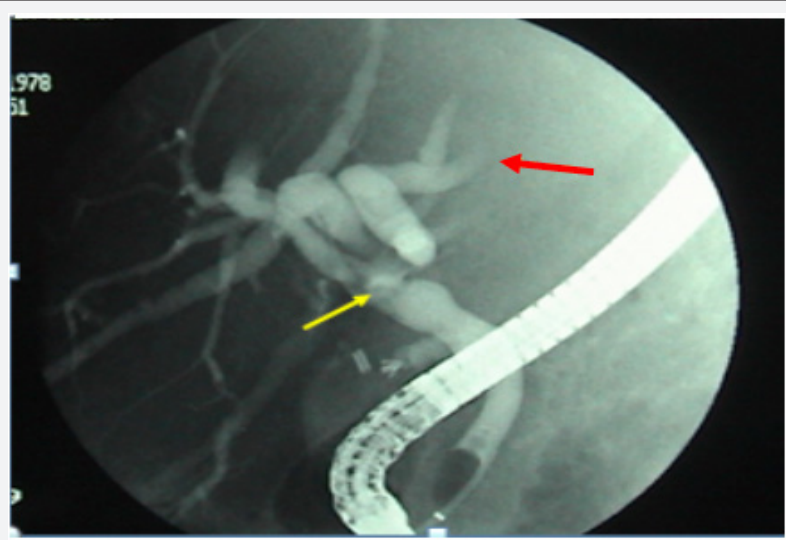

Figure 6: ERCP imaging showing a persistent common bile duct stenosis (yellow arrow) and a left hepatic duct stenosis with biliary tree amputation (red arrow). 


\section{Juniper Online Journal of Case Studies}

Seeing this clinical aggravation, we opted for surgical exploration. Right subcostal incision was made, the liver seemed cholestatic, a large $6 \mathrm{~cm}$ mass covering segments II and III was seen with a multitude of neighboring small abscesses (Figure 7). The left triangular ligament was cut for better visualization of the left liver. Multiple biopsies of the mass and abscesses were taken and sent for frozen studies and came back negative for malignancy. Left lobectomy using the ultracision scalpel was then performed (Figure 7). Using a Fogarty catheter, we explored the common hepatic bile duct with the left hepatic duct and extracted multiple necrotic debris with blood clots (Figure 8). Intrabiliary washing was performed, followed by intraoperative cholangiography, which showed biliary tree patency and subsequent duodenal emptying. A choledochoscope was then introduced and showed no signs of stenosis or debris with only minor inflammatory reactions to be noted. A Kehr drain was left in the common bile duct. Multiple biopsies were taken from the right liver lobe.

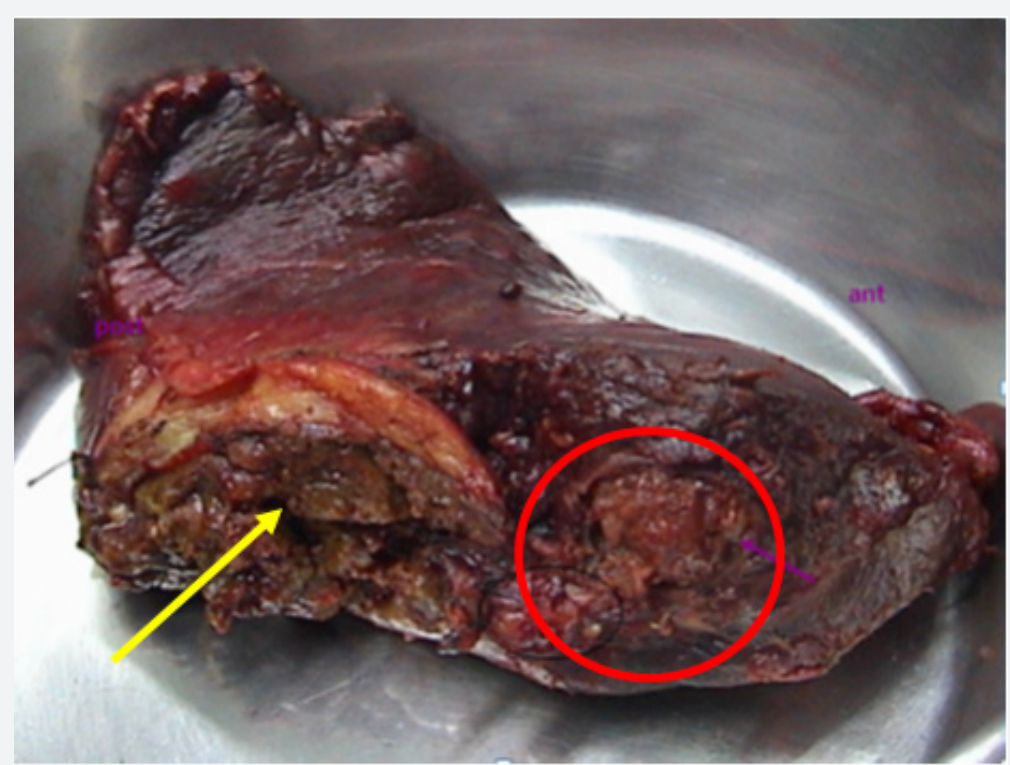

Figure 7: Surgical specimen of a left lobectomy showing the mass (yellow arrow) with neighboring abscesses (red circle).

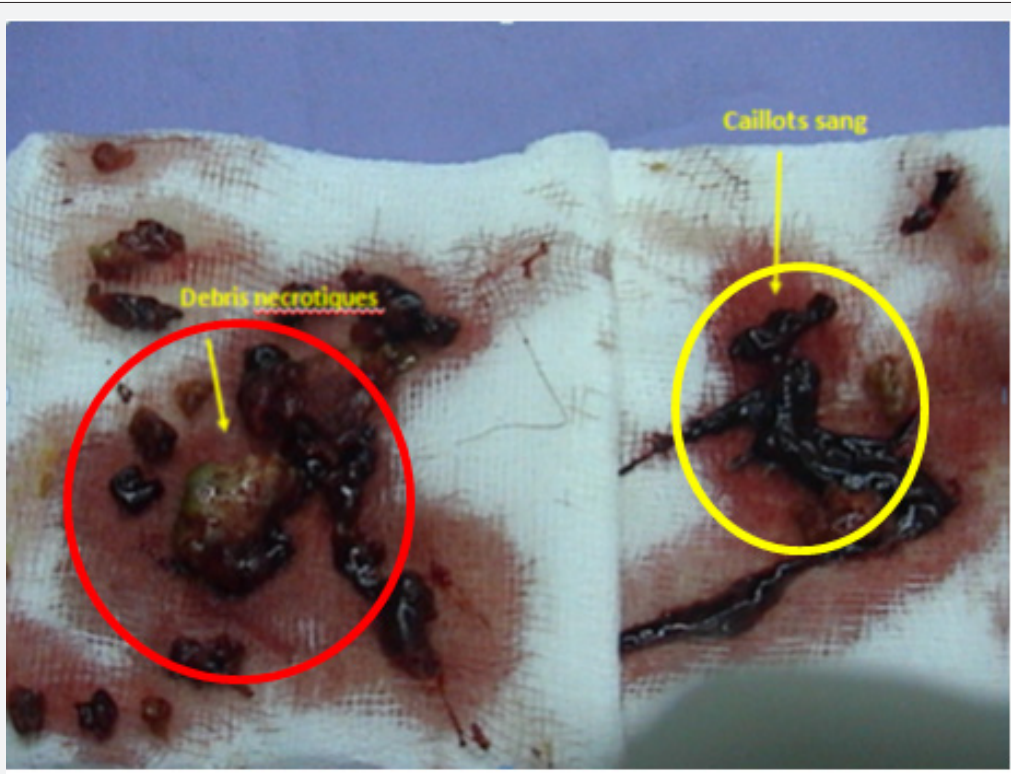

Figure 8: Picture showing findings following intraoperative exploration of common bile duct and left hepatic duct, necrotic debris (red circle) and blood clots (yellow circle).

Postoperative follow up was unremarkable. A cholangiography by the Kehr drain was performed seven days' post op and showed clear biliary tree patency. Patient had left the hospital on postoperative day 14 and the Kehr drain was removed 3 weeks following her day of discharge.
Pathology results came back positive for a well differentiated and necrotic hepatocellular carcinoma of the left liver lobe, with capsular invasion. The tumor was also invading the intrahepatic biliary ducts with presence of multiple small liver abscesses. The right lobe biopsies showed sclerotic lobulation but no cirrhosis. 


\section{Juniper Online Journal of Case Studies}

The biliary tree extracted debris represented fibrino-cruoric material containing masses of tumor cells.

To sum it all up, it was the case of an HCC arising from a healthy normal liver, and invading the biliary ducts causing tumor emboli and hemobilia.

\section{Discussion}

HCC presents itself with an obstructive jaundice with an incidence of $0.5-13 \%$, depending on the continent [1]. This topic is rarely mentioned in the western literature [3]. However, it is much more frequently encountered in the Far East [1-8]. Biliary tree obstruction can be provoked by multiple etiologies:

a) A rupture of the HCC in the biliary tree;

b) A direct invasion of the biliary tree by the tumor;

c) A portal thrombus invading the biliary tree;

d) Blood clot by hemobilia.

However, mostly described cases were by tumor or malignant lymphadenopathy extrinsic biliary compression [2].

Despite recent advancements in hepatobiliary imagery, this particular type of tumor is still much confused with cholangiocarcinomas [9], and choledocholithiasis (like our case) [2-5]. Treatment, however, differs HCC causing biliary emboli, cholangiocarcinoma and biliary tree lithiasis. If promptly and properly treated, HCC causing biliary emboli might have a better a prognosis than cholangiocarcinomas. The goal of this discussion is to review the literature of HCC causing jaundice and to outline a management algorithm.

It is primordial to start with an abdominal ultrasound (US) whenever facing an obstructive jaundice. It helps predict to a certain degree the type of obstacle (lithiasis, stenosis, malignancy, extrinsic compression), localizes the obstacle's location and its consequences in the biliary tree, and if present any association with the liver parenchyma [1]. Doppler US is also helpful in localizing hypervascularised tumors and in differentiating between biliary tree tumor emboli and portal system thrombus [1].

Cholangiography is widely used in delineating the biliary tree anatomy. It is either performed percutaneously by percutaneous transhepatic cholangiography (PTC) for high biliary tree localized lesions or by ERCP for low localized lesions [1]. In addition, it allows us to biopsy a suspected lesion, extract it if it is mobile (in the case of lithiasis, tumor emboli or blood clot) and to install a biliary drain if necessary. However, facing a strong suspicion of HCC, it is important to distinguish if the biliary tree obstruction is to do tumor emboli, blood clot or extrinsic compression (the latter having the worst prognosis). W Y Lau et al. [5] describes these 3 types of biliary obstruction using cholangiography [5]: type I represents biliary inclusion of tumor fragments which is marked by partial or complete obstruction of the common hepatic duct and the right or left hepatic ducts. Type II represents a blood clot logged in the biliary tree taking on the appearance of a flaky pile, less solid than type I and more dispersed throughout the biliary tree. Type II represents an extrinsic compression of the biliary tree and is characterized by the presence of a stenosis of the biliary tree with anatomical distortion of the biliary anatomy and proximal biliary dilation [5]. Type II may frequently benefit from cholangiography and extraction of the clot until diagnosing the etiology of the recurring disease (similar to our case) [5].

Cholangiographies, however, are operator dependent and are invasive procedures, carrying a risk of complications following manipulation of the biliary tree [2]. MRCP, on the other has the advantage of delineating the biliary anatomy without the risk of being invasive using the bile's concentration in water as contrast material. J-H. Tseng et al have use this imaging technique to classify the jaundice causing HCC into 3 types [2]:

a) Type 1 represent a $2-4 \mathrm{~cm}$ in diameter defect of the extra hepatic biliary tree causing dilation of the intra hepatic tree. Patients whom underwent multiple thrombectomies, exhibit the image of a small infiltrating tumor as well associated to multiple abscesses of the hepatic parenchyma, similar to our case.

b) Type II has the appearance of a dilated intrahepatic biliary tree with a radiologically absent main biliary tree. It corresponds to a lesion (clot or tumor) obstruction the whole of the hepatic carina with frequently the left and/or right hepatic duct.

c) Type III represents a stenosis localized at the hepatic carina. This type corresponds to a tumor hilar lymph node invading the segment I of the liver with the hilar plate and causing an external compression of the hepatic carina [2].

Thus, types defined by cholangiography are very similar to types by MRPC with the former having the advantage of not being invasive and has the possibility to rule out a portal thrombus by visualizing the portal trunk. MRPC also permits to distinguish the histological type obstructing the biliary tree (hemobila. Lithiasis, tumor...) based on the lesion's signal (hyper, hypo or iso) on T2.

Finally, having high level of AFP with a cirrhotic or chronic carrier of hepatitis B or C with obstructive jaundice, should guide us to rule in a HCC causing obstructive jaundice [1].

Fine needle aspiration of the biliary tree content for cytology, represents an officious and acceptably invasive, diagnostic procedure that would help in the diagnosis of a biliary tumoral thrombus without a clear primary tumor [10].

In conclusion, HCC causing obstructive jaundice is a rare entity that is difficult to diagnose. Based on the classifications of Lau et al. and Tseng et al., we now have the diagnostic tools to use when we have a high suspicion of HCC causing obstructive jaundice [24]. Cholangiography and/or MRCP will help us distinguish the nature of the biliary tree obstacle $[1,2,4,5]$.

a) Tumor emboli, fibrino-cruoric embolic and choledocholithiasis which can be easily treated by primary resection of the HCC and choledochotomy/biliary tree exploration (like our case) $[1,9,14]$. 
b) HCC invading through the biliary tree and causing their obstruction which carries a more morbid management plan tailored by a right/left hepatectomy with resection of the diseased primary biliary tree and extensive lymphadenectomy; this however carried mediocre prognosis $[1,4]$.

Extrinsic compression of the biliary by the HCC or the enlarged hilar lymph nodes, which render the tumor hardly respectable (neoadjuvant chemo/radiotherapy may be require with or without chemoembolization); this carries an even worse prognosis [3]. Finally, we must not forget the importance of MRCP in diagnosing a portal thrombosis associated with the icteric type HCC, giving the disease a bad prognosis and rendering management even more delicate [2].

\section{References}

1. Lai EC, Lau WY (2006) Hepatocellular carcinoma presenting with obstructive jaundice. ANZ J Surg 76(7): 631-636.

2. Tseng JH, Hung CF, Ng KK, Wan YL, Yeh TS, et al. (2001) Icteric-type hepatoma: magnetic resonance imaging and magnetic resonance cholangiographic features. Abdom Imaging 26(2): 171-177.

3. Huang JF, Wang LY, Lin ZY, Chen SC, Hsieh MY, et al. (2002) Incidence and clinical outcome of icteric type hepatocellular carcinoma. J Gastroenterol Hepatol 17(2): 190-195.

4. Tantawi B, Cherqui D, Tran van Nhieu J, Kracht M, Fagniez PL (1996) Surgery for biliary obstruction by tumour thrombus in primary liver cancer. British Journal of Surgery 83(11): 1522-1525.

5. Lau WY, Leow CK, Leung KL, Leung TW, Chan M, et al. (2000) Cholangiographic features in the diagnosis and management of obstructive icteric type hepatocellular carcinoma. HPB Surg 11(5): 299-306.
6. Huang GT, Sheu JC, Lee HS, Lai MY, Wang TH, (1998) Icteric type hepatocellular carcinoma: Revisited 20 years later. Journal of Gastroenterology 33(1): 53-56.

7. Makino T, Nakamori S, Kashiwazaki M, Masuda N, Ikenaga M, et al. (2006) An Icteric type hepatocellular carcinoma with no detectable tumor in the liver: report of a case. Surg Today 36(7): 633-637.

8. Shimada M, Takenaka K, Hasegawa H, Shirabe K, Gion T, et al (1997) Hepatic resection for icteric type hepatocellular carcinoma. Journal of Hepatogastroenterology 44(17): 1432-1437.

9. Eric Vibert, Denis Chatelain, Corrine Barrucand, Rosa Garavito, Thierry Yzet, et al. (2006) Récidive tardive d'un carcinome hépatocellulaire endo-biliaire sans tumeur intra-parenchymateuse détectable. EMC Gastroenterol Clin Biol 30(5): 790-793.

10. Huang JF, Chen SC, Wang LY, Yu ML, Dai CY, et al. (2006) Diagnosis of Icteric-Type Hepatocellular Carcinoma by Fine Needle Aspiration: A Case Report. Acta Cytol 50(5): 531-533.

11. Mok KT, Chang HT, Liu SI, Jou NW, Tsai CC, et al. (1996) Surgical treatment of hepatocellular carcinoma with biliary tumour thrombi. Int. Surg 81(3): 284-288.

12. Satoh S, Honda G, Okabe H, Takeyama O, et al. (2000) Clinicopathologic evaluation of hepatocellular carcinoma with bile duct thrombi. Surgery 128(5): 779-783.

13. Shiomi M, Kamiya J, Nagino M, Uesaka K, Sano T, et al. (2001) Hepatocellular carcinoma with biliary tumour thrombi: aggressive operative approach after appropriate preoperative management. Surgery 129(6): 692-698.

14. Qin LX, Ma ZC, Wu ZQ Fan J, Zhou XD, et al. (2004) Diagnosis and surgical treatments of hepatocellular carcinoma with tumor thrombosis in bile duct: Experience of 34 patients. World J Gastroenterol 10(10): 13971401.
Your next submission with Juniper Publishers will reach you the below assets

- Quality Editorial service

- Swift Peer Review

- Reprints availability

- E-prints Service

- Manuscript Podcast for convenient understanding

- Global attainment for your research

- Manuscript accessibility in different formats

( Pdf, E-pub, Full Text, Audio)

- Unceasing customer service

Track the below URL for one-step submission

https://juniperpublishers.com/online-submission.php 